\title{
No evidence for a rule/procedural deficit in German patients with Parkinson's disease
}

\author{
M. Penke ${ }^{\mathrm{a}, *}, \mathrm{U}_{\text {. Janssen }}{ }^{\mathrm{b}}$, P. Indefrey ${ }^{\mathrm{c}}$, R. Seitz ${ }^{\mathrm{d}}$ \\ a Institut fuer Sprache und Information, Universitaet Duesseldorf \\ ${ }^{\mathrm{b}}$ Institut fuer Germanistische Sprachwissenschaft, Universitaet Marburg \\ ${ }^{c}$ Peter Indefrey, F.C. Donders Centre for Cognitive Neuroimaging \\ ${ }^{\mathrm{d}}$ Ruediger Seitz, MNR-Klinik, Universitaet Duesseldorf
}

Accepted 8 July 2005

\section{Introduction}

In a series of papers, Ullman has proposed that a system of frontal/ basal ganglia circuits is implied in the learning and processing of grammatical rules (cf. Ullman, 2004; Ullman et al., 1997). Evidence for this view comes from past-tense inflection tasks in English-speaking Broca's aphasics and patients with Parkinson's disease where subjects displayed a selective deficit in the production of regular past-tense forms compared to the production of irregular forms (cf. Ullman et al., 1997). In previous studies, we have shown that, in contrast to English Broca's aphasia, a selective deficit with regular inflectional morphology cannot be observed in German and Dutch Broca's aphasia (Penke, Janssen, \& Krause, 1999; Penke \& Westermann, in press). Hence, contrary to Ullman's claim, Broca's area is not critically involved in regular inflection across languages. Here, we are going to present experimental results from 10 German subjects with Parkinson's disease, providing evidence that basal ganglia circuits, too, are not critically implied in German regular participle and noun plural inflection.

\section{Method}

We elicited regular and irregular participles and noun plurals from 10 right-handed German patients with Parkinson's disease (7 males, 3 females, mean age 62 years). Subjects were moderately to severely impaired in motor activity and did not show signs of dementia in neuropsychological testing. Subjects were tested during a stay at the university's hospital, where medication was interrupted to test motor activity before neurological surgery.

Subjects were asked to transform: (i) verb forms in the 1st person singular present tense into past-participle forms and (ii) singular nouns

\footnotetext{
The research reported in this paper was supported by German Science Foundation Grant SFB 282/C8 to Martina Penke.

* Corresponding author.

E-mail address: penke@phil-fak.uni-duessedorf.de (M. Penke).
}

into plural nouns. We tested 77 verbs (39 regular, 38 irregular) and 80 nouns ( 20 forms each for the regular suffixes $-s$ and $-n$ on feminine nouns and for the irregular forms -er and $-n$ on non-feminine nouns) in randomized order (see Penke \& Krause, 2002 and Penke et al., 1999 for details on the material). A group of seven unimpaired right-handed subjects (mean age 58 years) served as controls for this study.

\section{Results}

Table 1 presents the correctness scores for regular and irregular participles, and noun plurals obtained from test and control subjects. As can be seen from the table, the patients with Parkinson's disease obtained high correctness scores for regular as well as irregular participles and noun plurals. Statistical testing revealed no difference between control subjects and patients with Parkinson's disease in any of the four tested conditions (Mann-Whitney test, $p>.05$ each).

A comparison of the correctness scores for regular and irregular participles, respectively, regular and irregular noun plurals gives no indication of specific problems with regular inflected forms for subjects with Parkinson's disease. In contrary, both for participles and noun plurals correctness scores for regular inflected forms were slightly higher compared to the correctness scores for irregular inflected forms. On average, only $2.6 \%$ of the regular inflected participles and $3.5 \%$ of the regular noun plurals are not produced correctly. The corresponding error rates for irregular participles $(6.6 \%)$ and irregular noun plurals $(11 \%)$ are significantly higher (Wilcoxon test, $p=.011$ for comparison between regular and irregular participles, and for comparison between regular and irregular noun plurals). As can be seen from the individual data in Table 1, none of the subjects with Parkinson's disease displayed selective problems for regular inflected forms. For all subjects, correctness scores for regular inflected forms are either higher or equal to the correctness scores for the respective irregular forms.

Moreover, subjects made use of the regular default affixes $-t$ for participle inflection and $-s$ for plural inflection to produce participles, and noun plurals for irregular verbs and nouns (i.e., getrinkt instead of 
Table 1

Correctness scores for regular and irregular inflected participles and noun plurals

\begin{tabular}{|c|c|c|c|c|}
\hline & \multicolumn{2}{|l|}{ Past participles } & \multicolumn{2}{|l|}{ Noun plurals } \\
\hline & $\begin{array}{l}\text { Regular }(n=39) \\
\text { correct in } \%\end{array}$ & $\begin{array}{l}\text { Irregular }(n=38) \\
\text { correct in } \%\end{array}$ & $\begin{array}{l}\text { Regular }(n=40) \\
\text { correct in } \%\end{array}$ & $\begin{array}{l}\text { Irregular }(n=40) \\
\text { correct in } \%\end{array}$ \\
\hline US & 97.4 & 97.4 & 100 & 95 \\
\hline $\mathrm{CP}$ & 100 & 94.7 & 100 & 95 \\
\hline HS & 89.8 & 79 & 100 & 65 \\
\hline PD & 100 & 94.7 & 100 & 95 \\
\hline WS & 100 & 100 & 97.5 & 87.5 \\
\hline IT & 92.3 & 86.9 & 90 & 80 \\
\hline FM & 100 & 97.4 & 97.5 & 95 \\
\hline $\mathrm{HN}$ & 100 & 97.4 & 97.5 & 97.5 \\
\hline NB & 94.9 & 89.5 & 97.5 & 95 \\
\hline $\mathrm{FO}$ & 100 & 97.4 & 85 & 85 \\
\hline Total & 97.4 & 93.4 & 96.5 & 89 \\
\hline Controls $(n=7)$ & 99.6 & 97.4 & 98.6 & 95 \\
\hline
\end{tabular}

the correct irregular getrunken, or Nachbars instead of the correct irregular Nachbarn). In total, $76 \%$ of the 25 errors that subjects with Parkinson's disease committed with irregular verbs and $18.2 \%$ of the 44 errors with irregular nouns were such over-regularizations of the regular default affixes $-t$ and $-s .{ }^{1}$ This indicates that subjects were able to make productive use of the regular default affixes.

\section{Discussion}

Despite the close similarities between German and English inflectional systems, we found no evidence for a selective deficit affecting the production of regular inflected forms in 10 German subjects with Parkinson's disease. This finding is in contrast to the results reported for English-speaking subjects with Parkinson's disease who displayed a selective impairment in producing regular past-tense forms (Ullman et al., 1997). By contrast, the data of our German subjects indicate that the findings on regular past-tense inflection in English Parkinson's disease do not hold across languages. This suggests that the basal ganglia are not crucially involved in the production of regular inflected forms.

\section{References}

Penke, M., Janssen, U., \& Krause, M. (1999). The representation of inflectional morphology. Brain and Language, 68, 225-232.

Penke, M., \& Krause, M. (2002). German noun plurals: A challenge to the dual-mechanism model. Brain and Language, 81, 303-311.

Penke, M., \& Westermann, G. (in press). Broca's area and inflectional morphology: Evidence from Broca's aphasia and computer modeling. To appear in Cortex.

Ullman, M. T. (2004). Contributions of memory circuits to language: The declarative/procedural model. Cognition, 92, 231-270.

Ullman, M. T. et al. (1997). A neural dissociation within language. Journal of Cognitive Neuroscience, 9(2), 266-276.

\footnotetext{
${ }^{1}$ The system of German noun plurals consists of five different plural markers. Whereas $-s$ is the default marker, applied to words that do not yet have a lexical entry, many subjects prefer the marker $-e$ to produce plural forms for monosyllabic masculine and neuter nouns. $75 \%$ of the 44 errors committed with irregular nouns resulted in an incorrect $-e$ inflected form.
} 